\title{
Mathematical Modeling of Network Auxiliary Project Based on Optimization Inspection
}

\author{
Cuihuan Liu \\ Department of Electronics and Information Technology, Shijiazhuang City Vocational College \\ Shijiazhuang, China, \\ I_iucuihuan@126.com
}

Keywords:network-assisted ; project teaching ; mathematical model ; optimize test

\begin{abstract}
The goal of education modernization is that education hardware and software modern can be synchronous, constructivism mainly is reflected as the subjectivity of students in the process of education teaching, let the students actively construct knowledge structure in the learning process, master the whole teaching content in the whole teaching plan and the extension of teaching plan through autonomous learning. This paper has analysed the significance constructivism theory to modern education teaching based on the analysis of the theory of constructivism, the use of mathematical modeling ideas constructed mathematical model to research the teaching integration advantages of constructivism and network aided project teaching, then further deepen the network aided project teaching method of constructivism's building, it is concluded that scientific and rational modern teaching concept and strategy, has provided certain theoretical basis and the practical path for the research of this area.
\end{abstract}

\section{Introduction}

Since the Swiss piaget (J.P iaget) has put forward the constructivism theory in twenty century, this theory aroused a wide range of positive influence in Switzerland and even within the scope of the world, and quickly developed into the important guiding ideology of western countries education reform direction and development direction[1]. As China is in situation of the deepening of education reform and the full implementation of the quality education, constructivism theory research is far from enough, especially the application teaching research of the constructivism theory in modern Chinese education teaching reform is limited to some fields.

The practice influence and effect analysis to constructivism teaching theory of the XueGuoFeng, mainly make the development of constructivism teaching theory as a theoretical basis, through the management mode of school, the teacher teaching and teaching reform and the others influence factors to analysis the influence of the teaching practice based on constructivism; The constructivism teaching conditions of ZhaoMengcheng,start from the relationship between democratic teachers and students consciousness, in view of constructivist teaching foundation,it provided a new thinking based on the knowledge of students learning, the training of learning ability ,class management and the formation of the team consciousness, and at the same time, it emphasis that constructivism teaching conditions has an effects on divergent thinking ability, knowledge framework systematic and clear learning goals in a timely manner and the teaching effect evaluation[2].The implementation of constructivism is able to raise the team cooperation ability of individual and the teacher's guidance ability, then promote the friendship of teachers and students, and can also more efficient constructed the study methods in constructivism teaching mode; The constructivism teaching of Ma Wanhua has a revelation to the reform of university, it mainly introduces the latest western education psychology theory,( constructivism theory), which also emphasized the constructivism teaching theory is a new kind of teaching mode, it is not only a philosophical concept, break through the traditional concept of teaching mode, involves various contents of teaching knowledge, and at the same time,it puts forward the construction of teaching theory is the teaching theory should be paid attention in China's university education reform and innovative personnel training;

ChenLiWei has put forward a new teaching mode which can promote personalized autonomous learning, the innovation of higher vocational English-a discussion of college English multimedia 
network aided teaching based on constructivism teaching theory, this paper mainly discusses the English teaching situation of contemporary higher vocational technical college, with the process of English teaching reform practical applicatio in Anhui vocational and technical college as an example, detailed analysis the constructivism teaching theory plays an important role to university college in multimedia network aided teaching English teaching methods, through the analysis we pointed out that the theory can effectively promote the vocational college students' individualized English learning ability; Gu Peiya, Fang Ying based on constructivism computer aided project teaching practice emphasis on the core of constructivism learning theory is the building, its basic method is the clear goal, the upright attitude, the thought is open, interactive cooperation, clear task, active, and through a teaching reform practice of the suzhou university students whose major are foreign trade English, the improve teaching effect of constructivism in computer aided project teaching mode, the effectiveness of the constructivism teaching theory have a certain impact to Chinese traditional teaching methods, which make the foreign language teachers face some challenges and opportunities[3].

\section{The significance of constructivism theory in modern education teaching}

Constructivism (constructivism theory )is full of materialist dialectics, originate from children's cognitive theory, this theory mainly focuses on the interaction of internal and external, they think the child is gradually construct the knowledge about the outside world in the process of the interaction to the surrounding environment, and, so that their own cognitive structure can well developed[4]. The learners in the learning process ,the personal cognitive of students individual is also related to the whole learning process, they will also build a note applied to modern education teaching practice and this student can also elaborate the individual cognition and learning rule in the process of learning knowledge to some extent .The whole application to education teaching process as below.

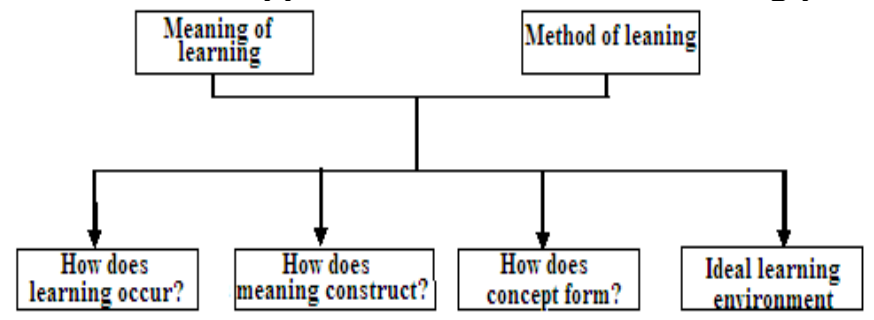

Figure 1. The education teaching process diagram under constructivism theory

As shown in Figure 1, first learners need to cognize the meaning of constructivism theory in the education teaching process, and dig their own learning thought, at the same time constructe learning method framework in the process of cognitive[5]. We can analyse the influence factors in the whole learning process under the guidance of constructivist learning theory, such as how did the whole learning process happen, analyse the intrinsic and extrinsic factors of the study, and the interaction between them that fusion the external factor into the whole learning process of cognition; With the application of constructivism thought analysis and the significance of constructivism learning, and transfer the adverse factors which will affect learning into the positive factors that are conducive to learning; then form the related learning concept, and summarizes the similar sites or attribute and characteristics of knowledge, through them we can constitute all kinds of knowledge default category, can form the prototype structure of the current knowledge; Construct an ideal learning environment that is "assimilation" and "adjustment", through concept, default performance of the prototype structure knowledge, through structure of the default performance we can find the relationship between the related knowledge of the knowledge, show the characteristics of the current knowledge, the edge attribute of the knowledge and adjacent category attributes cross each other, so as to construct an ideal learning environment.

Modern education teaching has introduced the constructivism theory which can not only change the shortcomings of the traditional teaching that mainly depend on the teachers, but also can effectively improve the modern teaching achievement, more likely can promote the all-round development of students' abilities,and cultivate the students' comprehensive quality, Based on the characteristics of contemporary college students,the teachers can effectively guide the characteristics of students' personality traits develop into be the good aspects of learning ,at the same time we can 
analysis the personalized characteristic feature in the process of teaching, further deepening the constructivism theory and make it is consistent with the overall development of modern teaching outline; In the whole teaching process,the use of constructing socialist can optimize the teaching concept, expand the teaching content, and optimize the teaching mode; give full play to the students' subjective role, decompose teaching target structure and combine diversity to promote students' self fulfillment, such as promoting thematic teaching, students' individual learning team, the team established the combination with teaching of the whole discussion and individual teaching discussion and carry out cooperation and mutual aid, the new mode of individual and group learning[6]. Break the traditional teaching process study mainly depend on the teachers, students, the interaction of teaching content elements form the closed circle of role, and diverge the content of the study, summed up and summarized form new optimization mode of learning, and further promote various intelligence development of various contemporary students in the learning process

\section{The integration advantage analysis of constructivism and network aided project teaching}

\section{A. Project teaching}

Project teaching method originated in Europe's ideological education, after the development and perfection of approved education and cooperation education, and finally become the most important kown thoughts of the contemporary education. Project teaching points to the whole process of the student individual independently complete a separate the project under the guidance of the teacher ,the process of the middle school students independently complete the project process we need to master the all the teaching content in the plan of syllabus, the students should independent arrange students task, self-discipline their learning behavior[7]. Project teaching method can improve the students' study interest in a certain extent, arouse the enthusiasm of the whole study, play to their biggest advantage of learning, cultivate the ability of sketch independent problem-solving, is a typical kind of student-centered teaching mode.

The most main characteristic of project teaching method is to change the passive relations between teachers and students in traditional teaching mode, with the project as the leading factor, teachers as the guidance, the students as the main characteristics, specific as below.

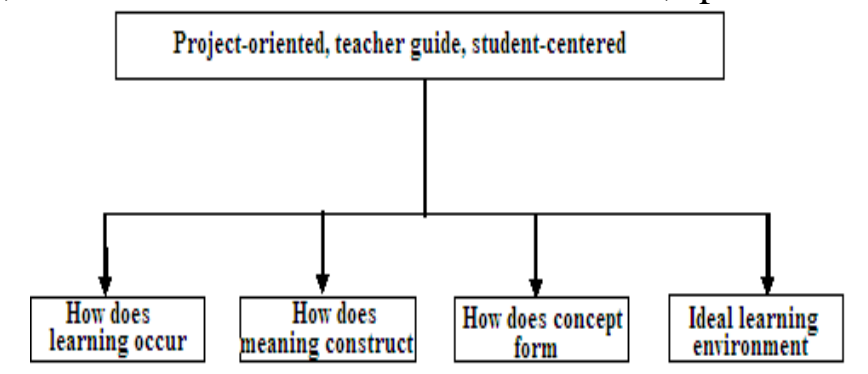

Figure 2. The teaching mode of project teaching method

As shown in Figure 2, multiple target means change the students's learning way in the teaching process, highlight the subjectivity of students, actively cultivate their interest in the learning environment, to stimulate their learning inspiration, enhance their practical ability, develop their own field of vision; Short learning cycle has a quick effect refers to the project teaching method is teaching activities in fixed period,we can periodic evaluate the teaching effect; Controllability is refers to not only teachers and students to participate in the project teaching method, and at the same time, students' independently learning activities on the basis of with the teacher's guidance, students can better focus to complete the study task; Pay attention to combining theory with practice is refers to the individual student complete a teaching project are made by themselves and participate in independently, first think of themselves when solve the problem, the second is the teacher's guidance,so that students can firstly analyzes the problem of related principles in solving the problem, then deepen analysis operation step by step[8].

B. The integration advantages of constructivism and network aided project teaching

Constructivism and network aided project teaching integration means change the traditional teaching model, students will no longer only depend on teacher's instruction, teachers will no longer 
take imparting their existing knowledge to students as its teaching goal, instead, teachers provides guidance to teaching in the teaching process, students through the network aided to finish her project path and method. Constructivism and network aided project teaching integration process will construct socialist teaching theory set parameters ${ }_{0}$, the network aided project teaching set parameters $x_{1}$, integration effect parameter of constructivism and network aided project teaching is $x_{2}$, it is $x\left(t_{0}\right)=x_{0}, x\left(t_{1}\right)=x_{1}, x\left(t_{2}\right)=x_{2}$, among them $t_{1}-t_{0}=t_{2}-t_{1}=\tau$, the two organic integration model can get[9]:

Solution to,

$$
x_{1}=\frac{a x_{0}}{b x_{0}+\left(a-b x_{0}\right) e^{-a \tau}} \quad x_{2}=\frac{a x_{1}}{b x_{1}+\left(a-b x_{1}\right) e^{-a \tau}}
$$

$$
a=\frac{1}{t} \ln \frac{x_{2}\left(x_{1}-x_{0}\right)}{x_{0}\left(x_{2}-x_{1}\right)} ; \quad b=\frac{a\left(x_{0} e^{a \tau}-x_{1}\right)}{x_{0} x_{1}\left(e^{a \tau}-1\right)}
$$

Set $x(\bar{t})=\frac{a}{2 b}$, then we can get $e^{-a\left(\bar{t}-t_{0}\right)}=\frac{b x_{0}}{a-b x_{0}}$, students need define their own independent problem solutions and technical route protocol in the learning process, to complete their projects, evaluate the learning outcome which combinate individual learning during the individual study of project and self evaluation. The whole teaching mode need to pay more attention to students' learning process rather than learning outcome, by means of network can they exercise their various aspects ability in the learning process, students are absolute the main body of the position in the learning process, the teacher is only the guide and the overseer of students in the process of learning,in this mode ,students may have a great study enthusiasm. It is with formula (1) approximate form simple expression[10]:

$$
x(t)=\frac{a / b}{1+e^{-a(t-\bar{t})}}
$$

In formula (3) ,we can dig out for the concern of education workers, organically change their teaching methods and ideas, which reflect the thought of give the fish into give fish, from the giver to the guider in the students learning process, promoters, and supervisor.Concerned for the education management organization, system innovation, the teaching mode innovation is an effective means to improve the teaching effect, and it is also the new path that tries to promote the teaching goal. Constructivism and network aided project teaching integration can explore new teaching mode, enrich the teaching content, outstanding the management experience, perfect teaching evaluation, complete hardware, develop teaching software, reform the teaching system and integrate curriculum content.

\section{Optimization of network-assisted teaching of constructivism}

Constructivism holds that knowledge received not by teachers teaching, but learners in certain situations namely the social and cultural background, with other people's(including teachers and learning partners) help to make use of the necessary learning information by way of the construction of meaning obtained .

In the process of practical teaching, network-assisted project teaching mode of constructivism grasps the knowledge and thought consciousness in macroscopic and microcosmic simultaneously, and better integration of learning content, learning method adjustment, that the current courses of study and learning of other subjects are able to achieve excellent results, at the same time to make the whole course teaching has characteristics including the Profound , flexibility, openness etc.The integration of constructivism and network-assisted project teaching method of teaching awareness is the starting point of people engaged in innovation activities and motivations, it's a psychological orientation of pinpointing the problems and active exploration.

Therefore, it from another perspective can optimize the mathematical model by constructing constructivism network-assisted project teaching, on the Malthus model, plus a competition $-b x^{2}(b>0)$, to upgrade the effect of the network-assisted teaching.If the level of the entire country 's teaching developed, well equipped hardware facilities, and it can provide efficient support for the network-assisted project teaching mode of constructivism, then B is smaller; on the contrary, B is larger, so the establishment of optimization equation is[11]: 


$$
\left\{\begin{array}{l}
\frac{d x}{d t}=x(a-b x),(a, b>0) \\
x\left(t_{0}\right)=x_{0}
\end{array}\right.
$$

We can obtain the following formula:

$$
\begin{aligned}
& x(t)=\frac{a x_{0}}{b x_{0}+\left(a-b x_{0}\right) e^{-a\left(t-t_{0}\right)}} \\
& 12]: \frac{d^{2} x}{d t^{2}}=(a-2 b x) x(a-b x)
\end{aligned}
$$

By the formula (1) (2),we can be obtained[12]: $\frac{d^{2} x}{d t^{2}}=(a-2 b x) x(a-b x)$ (3)

The integration of constructivism and network-assisted project teaching can improve the traditional teaching's drawbacks, break through the limitations, when students encounter problems in the learning process, it is possible by means of teaching aids to find a solution scheme and implementation path from multiaspect and multi-angle, the more important thing is to cultivate students' comprehensive awareness and spirit in the teaching process by the new learning methods and thinking model, to integrate the elevation of students' enthusiasm for learning and practical ability by new teaching methods.

It can be obtained by the formula (1), (2), (3), we can get :

when $\forall t>t_{0}$, then $x(t)>0$, and $\lim _{t \rightarrow+\infty} x(t)=\frac{a}{b}$

when ${ }^{0<x<\frac{a}{b}}$, then $x^{\prime}(t)>0, x(t)$ it increases steadly; when $x=0$, then $x^{\prime}(t)=0$; when ${ }^{x>\frac{a}{b}}$, then $x^{\prime}(t)<0, x(t)$ it decreases steadly;

when $^{0<x<\frac{a}{2 b}}$, then $x^{\prime \prime}(t)>0, x(t)$ is concave, when $\frac{a}{2 b}<x<\frac{a}{b}$, then $x^{\prime \prime}(t)<0, x(t)$ is convex.

Set the right side of the formular( 1) as 0 , obtained $x_{1}=0, x_{2}=\frac{a}{b}$, they are called the equilibrium solution of this differential equation, it can be seen $\lim _{t \rightarrow+\infty} x(t)=\frac{a}{b}$, so regardless what the number of students ${ }^{x_{0}}$, after quite a long time, the integration of constructivism and network-assisted projects teaching can inspire students daring to innovate , question and criticize in the process of learning; explore the students' independent thinking ability and the wealthy individual featured understanding and expression ability.

In the practical process of integration of constructivism and network-assisted project teaching, it can take advantage of the network-assisted research to tap the abundant resources of learning; it exerts the concerning of the project teaching model to develop and cultivate the potential of each student, cultivate independent personality, thought and stimulate the students' creative ability to get better teaching results; the introduced teaching which based on the constructivist can break through the traditional teaching mode,to make each and every student take part in the practice of teaching, provide each student the opportunity and try to experience success.

\section{Conclusion}

The network-assisted project teaching which based on constructivism actually is an education form that established in the background of information society, its main content integrated production and social unity, its main goal is to socialize the learner's study behavior, that the learners can meet the needs of modern education and mutual unification relations of modern social production productivity.The goal of cultivating talents is applied talents, namely the practice of practical talents.For the modernization of education,it can in some sense enlighten people rethinking education, evoke educators revisiting of current education.

\section{References}

[1] XueGuofeng.Constructivism teaching theory practice influence and effect analysis. Foreign Education,2011(11):39-42.

[2] Zhao Mengcheng. Constructivism teaching conditions . Higher Education research, 2012(5)7779. 
[3] Ma Wanhua. Constructivism teaching reform of university of enlightenment.Journal of Wuhan University,2012(9):67-69.

[4] Chen Liwei. Promote personalized autonomous learning.Promoting individualized autonomous learning, innovation of Higher Vocational English teaching model based on Constructivism Theorythe University English Multimedia Network Aided Teaching.Journal of Anhui vocational technical college,2012(9):68-71.

[5] Gu Peiya,FangYing,Constructivism Based Computer Aided Project Teaching Practice.Foreign language and foreign language teaching,2010(8):103-106.

[6] Zhang Jianwei,Chen Qi.From cognitivism to constructivism.Journa of Beijing Normal University (Social Science),2009(4): 75-82.

[7] Wang Weirong.Representation of history:Six Strong Constructivism Measures-the new measures of the history teaching reform of the United States. Journal of Subject Education,2010(07):34-38.

[8] Liu Rude 7 problem-based learning:A concentrated reflection of the thoughts of constructivism teaching reform thinking.Theory and Practice of Education,2011(5):98-102.

[9] Jia Huaiqin.Data, Modeling and Decision.University of International Business and Economics Press,2009:371-380.

[10] Qiu wanhua. Management decision making and application of entropy to learn.China Machine Press, 2002:178-198.

[11] Wilson, B. G. Metaphors for instruction Why we talk about learning environments . Educational Technology, 2010 (10):73-75.

[12] Hamsiah Mohd Dahalan.Development of Web-Based Assessment in Teaching and LearningManagement System (e-ATLMS).Procedia Social and Behavioral Sciences ,2010):244-248. 